\title{
Satzung
}

(Nach den Beschlüssen vom 21. Oktober 1949, 19. Oktober 1951,

14. Oktober 1954, 10. Oktober 1956, 13. Oktober 1960,

5. Oktober 1962, 1. Oktober 1971, 6. Oktober 1976,

3. Oktober 1979 und 6. Oktober 1999)

$\S 1$

Die Vereinigung der Deutschen Staatsrechtslehrer stellt sich die Aufgabe:

1. wissenschaftliche und Gesetzgebungsfragen aus dem Gebiet des öffentlichen Rechts durch Aussprache in Versammlungen der Mitglieder zu klären;

2. auf die ausreichende Berücksichtigung des öffentlichen Rechts im Hochschulunterricht und bei staatlichen und akademischen Prüfungen hinzuwirken;

3. in wichtigen Fällen zu Fragen des öffentlichen Rechts durch Eingaben an Regierungen oder Volksvertretungen oder durch schriftliche Kundgebungen Stellung zu nehmen.

$\S 2$

Mitglied der Vereinigung kann werden, wer auf dem Gebiet des Staatsrechts und mindestens eines weiteren öffentlich-rechtlichen Fachs

a) seine Befähigung zu Forschung und Lehre durch hervorragende wissenschaftliche Leistung nachgewiesen hat ${ }^{1}$ und

b) an einer deutschen oder deutschsprachigen Universität ${ }^{2}$ oder der Hochschule für Verwaltungswissenschaften in Speyer als Forscher und Lehrer tätig ist oder gewesen ist.

\footnotetext{
${ }^{1}$ Mit der oben abgedruckten, am 1. 10. 1971 in Regensburg beschlossenen Fassung des $\S 2$ hat die Mitgliederversammlung den folgenden erläuternden Zusatz angenommen. „Eine hervorragende wissenschaftliche Leistung im Sinne dieser Vorschrift ist eine den bisher üblichen Anforderungen an die Habilitation entsprechende Leistung.“

${ }^{2}$ In Berlin hat die Mitgliederversammlung am 3. 10. 1979 die folgende zusätzliche Erläuterung aufgenommen:

„Universität im Sinne dieser Vorschrift ist eine wissenschaftliche Hochschule, die das Habilitationsrecht in den Fächern des öffentlichen Rechts und die Promotionsbefugnis zum Doctor iuris besitzt und an der Juristen durch einen Lehrkörper herkömmlicher Besetzung ausgebildet werden.“
} 
Das Aufnahmeverfahren wird durch schriftlichen Vorschlag von drei Mitgliedern der Vereinigung eingeleitet. Ist der Vorstand einstimmig der Auffassung, daß die Voraussetzungen für den Erwerb der Mitgliedschaft erfüllt sind, so verständigt er in einem Rundschreiben die Mitglieder von seiner Absicht, dem Vorgeschlagenen die Mitgliedschaft anzutragen. Erheben mindestens fünf Mitglieder binnen Monatsfrist gegen die Absicht des Vorstandes Einspruch oder beantragen sie mündliche Erörterung, so beschließt die Mitgliederversammlung über die Aufnahme. Die Mitgliederversammlung beschließt ferner, wenn sich im Vorstand Zweifel erheben, ob die Voraussetzungen der Mitgliedschaft erfüllt sind. Von jeder Neuaufnahme außerhalb einer Mitgliederversammlung sind die Mitglieder zu unterrichten.

\section{$\S 3$}

Eine Mitgliederversammlung soll regelmäßig einmal in jedem Jahr an einem vom Vorstand zu bestimmenden Ort stattfinden. In dringenden Fällen können außerordentliche Versammlungen einberufen werden. Die Tagesordnung wird durch den Vorstand bestimmt. Auf jeder ordentlichen Mitgliederversammlung muß mindestens ein wissenschaftlicher Vortrag mit anschließender Aussprache gehalten werden.

$$
\S 4^{3}
$$

Der Vorstand der Vereinigung besteht aus einem Vorsitzenden und zwei Stellvertretern. Die Vorstandsmitglieder teilen die Geschäfte untereinander nach eigenem Ermessen. Der Vorstand wird von der Mitgliederversammlung auf zwei Jahre gewählt. Zur Vorbereitung der Jahrestagung ergänzt sich der Vorstand um ein Mitglied, das kein Stimmrecht hat. Auch ist Selbstergänzung zulässig, wenn ein Mitglied des Vorstandes in der Zeit zwischen zwei Mitgliederversammlungen ausscheidet. Auf der nächsten Mitgliederversammlung findet eine Nachwahl für den Rest der Amtszeit des Ausgeschiedenen statt.

\section{$\S 5$}

Zur Vorbereitung ihrer Beratungen kann die Mitgliederversammlung, in eiligen Fällen auch der Vorstand, besondere Ausschüsse bestellen.

\footnotetext{
$3 \S 4$ in der Fassung des Beschlusses der Mitgliederversammlung in Heidelberg vom 6. 10. 1999; in Kraft getreten am 1. 10. 2001.
} 


\section{$\S 6$}

Über Eingaben in den Fällen des $\S 1$ Ziffer 2 und 3 und über öffentliche Kundgebungen kann nach Vorbereitung durch den Vorstand oder einen Ausschuß im Wege schriftlicher Abstimmung der Mitglieder beschlossen werden. Ein solcher Beschluß bedarf der Zustimmung von zwei Dritteln der Mitgliederzahl; die Namen der Zustimmenden müssen unter das Schriftstück gesetzt werden.

\section{$\S 7$}

Der Mitgliedsbeitrag wird von der Mitgliederversammlung festgesetzt. Der Vorstand kann den Beitrag aus Billigkeitsgründen erlassen. 
